\title{
Australian Twin Registry: 30 Years of Progress
}

\author{
John L. Hopper, ${ }^{1}$ Debra L. Foley, ${ }^{2}$ Paul A. White, ${ }^{3}$ and Vincent Pollaers ${ }^{4}$ \\ ${ }^{1}$ Centre for Molecular, Environmental, Genetic and Analytic Epidemiology, University of Melbourne, Melbourne, Australia \\ ${ }^{2}$ Orygen Youth Health Research Centre, Centre for Youth Mental Health, University of Melbourne, Melbourne, Australia \\ ${ }^{3}$ Centre for Genetic Epidemiology and Biostatistics, University of Western Australia, Perth, Australia \\ ${ }^{4}$ Advisory Board, Australian Twin Registry, Melbourne, Australia
}

\begin{abstract}
The Australian Twin Registry (ATR) is a national volunteer resource of twin pairs and higher-order multiples willing to consider participating in health, medical, and scientific research. The vision of the ATR is 'to realize the full potential of research involving twins to improve the health and well-being of all Australians'. The ATR has been funded continuously by the National Health and Medical Council for more than 30 years. Its core functions entail the recruitment and retention of twin members, the maintenance of an up-to-date database containing members' contact details and baseline information, and the promotion and provision of open access to researchers from all institutes in Australia, and their collaborators, in a fair and equitable manner. The ATR is administered by The University of Melbourne, which acts as custodian. Since the late 1970s the ATR has enrolled more than 40,000 twin pairs of all zygosities and facilitated more than 500 studies that have produced at least 700 peer-reviewed publications from classical twin studies, co-twin control studies, within-pair comparisons, twin family studies, longitudinal twin studies, randomized controlled trials, and epigenetics studies, as well as studies of issues specific to twins. New initiatives include: a Health and Life Style Questionnaire; data collection, management, and archiving using a secure online software program (The Ark); and the International Network of Twin Registries. The ATR's expertise and 30 years of experience in providing services to national and international twin studies has made it an important resource for research across a broad range of disciplines.
\end{abstract}

Keywords: epigenetics, higher order multiples, International Network of Twin Registries, research enabling, The Ark, twin pairs

The Australian Twin Registry (ATR) was established in the late 1970s as a national volunteer registry of Australian twin pairs of all zygosity types and ages (Hopper et al., 2006). Its vision is 'to realize the full potential of research involving twins to improve the health and well-being of all Australians'.

The ATR has received continued support from the National Health and Medical Research Council (NHMRC) since 1981 and is currently funded by an Enabling Grant for 2010-2014. Twins are eligible to join regardless of their health or medical history. Researchers are eligible to apply irrespective of geographical location, institute, or discipline. The ATR manages information from more than 40,000 enrolled twin pairs and higher order multiples (HOMs) and provides researchers with access to members suitable, or potentially suitable, for approved studies once the twins have agreed to participate. Its core functions are the maintenance of an up-to-date database containing contact details and baseline information for twin pairs willing to consider participating in research projects, and the management of access to that resource in ways that enhance research capacity in a fair and equitable manner while protecting the rights of twins. Over the last 30 years the ATR has continued to grow in size and in terms of the benefits it offers to the research and twin communities. Many institutes supported by the ATR have generated numerous and varied studies resulting in a large volume of publications (see Table 2).

\section{Objectives}

The ATR acts as a facilitator and an enabler, providing an important national and international resource for health,

RECEIVED 31 August 2012; ACCEPTED 17 October 2012. First published online 3 December 2012.

ADDRESS FOR CORRESPONDENCE: John L. Hopper, Centre for Molecular, Environmental, Genetic and Analytic Epidemiology, The University of Melbourne, Level 3, 207 Bouverie St, Carlton, VIC 3010, Australia. E-mail: j.hopper@unimelb.edu.au 
medical, and scientific research across a wide range of disciplines. Its broad aim is to enable twin studies of the impact of genetic and environmental factors on health, and on the treatment and prevention of disease. As an openly shared resource, the ATR provides researchers with access to an established infrastructure and a network of scientists and administrative staff who are experienced in twin research.

The ATR's objectives are to:

1. Provide and deliver a comprehensive suite of research support services that enable and optimize the involvement of twins in research of high scientific merit;

2. Provide ATR members with a positive and rewarding membership experience so as to ensure their rights and well-being are protected, their contribution is enabled, and their continued support and ongoing membership is fostered; and

3. Promote the benefits and values provided by scientific research that accesses the unique benefits delivered through involving twins in studies.

\section{Operating Model}

\section{Governance and Management}

The ATR has an independent Board, instituted in 2005, that is currently chaired by an ATR twin member, Vincent Pollaers. The purpose and functions of the Board are set out in its Charter (www.twins.org.au/aboutus/overview/governance), and are to provide ATR management with guidance, support, and direction in its endeavors to facilitate and support research studies that involve the participation of twins, and for some studies their relatives, while protecting the rights of the ATR stakeholders. The composition of the Board ensures that the rights and interests of twins, their relatives, twin associations, and researchers are represented. The ATR invites a member of the Australian Multiple Birth Association (AMBA), a support group for twin families, to be on the Board.

The ATR is administered through The University of Melbourne, as custodian, and managed by a director, who is currently supported by two deputy directors. The ATR operations benefit from experienced staff who support the needs of researchers and twins in an enthusiastic, efficient, and consistent manner.

ATR management has benefited from the recent addition of a study coordinator to focus on research support and study development. This reflects the increased emphasis the ATR is placing on improving its research support services.

The ATR has also benefited from the appointment in 2011 of a marketing and communications officer. The importance of effective communication with twin members, prospective twin members, researchers, institutes, and other parties prompted the creation of this new role. As a result, the ATR has enjoyed considerable success in increasing
TABLE 1

Breakdown of the ATR by Zygosity Status and Gender Type

\begin{tabular}{lllll}
\hline Gender type & MZ & DZ & Unknown & $\begin{array}{c}\text { Overall proportion } \\
\text { of twins in ATR }\end{array}$ \\
\hline Female/female & $22 \%$ & $17 \%$ & $3 \%$ & $42 \%$ \\
Male/male & $16 \%$ & $15 \%$ & $2 \%$ & $33 \%$ \\
Male/female & - & $25 \%$ & - & $25 \%$ \\
Total & $38 \%$ & $57 \%$ & $5 \%$ & $100 \%$ \\
\hline
\end{tabular}

awareness of the ATR and in promoting the merits of scientific research involving twins.

\section{Informatics}

The work of the ATR is supported by a comprehensive relational database, which retrieves updated membership data to allow accurate record keeping of contact details and study participations. All work performed for researchers is logged and analyzed using this database, and reports generated to provide meaningful analysis of trends.

\section{ATR Twin Registry Services}

Our twin membership is comprised of more than 40,000 twin pairs and HOM. The average age of members is 34 years (age range from 1 month to 99 years), with $24 \%$ under the age of 18 years (Figure 1 ).

Figure 2 shows that the distribution of twin members across the states and territories is similar to that of the general population of Australia (as reported by the Australian Bureau of Statistics, 2011), although for historic reasons there are proportionally more members from Victoria and Western Australia and fewer from New South Wales and Queensland.

\section{Zygosity Determination}

Zygosity is determined at registration by a self-report questionnaire completed by twins, or parents of twins if the twins are under the age of 18 years, which assesses confusion regarding identity by family, friends, and strangers, and physical similarity (Torgersen, 1979). Twin pairs for whom the zygosity reports conflict or are undetermined are classified as unknown (Table 1).

\section{Twin Recruitment}

Twin pairs are registered via completion of a registration form online (currently $53 \%$ ), by paper (21\%), or over the phone (26\%) by either the twins or by their parents if the twins are under the age of 18 years. The majority of new members (85\%) are aged 0-9 years, a feature that has remained relatively consistent over the last 20 years.

Continuous recruitment of new twin members is vital to ensure the future viability of the ATR. The ATR's goal is to increase its membership from approximately $17 \%$ of the Australian twin population to $20 \%$ over the next 5 years. 


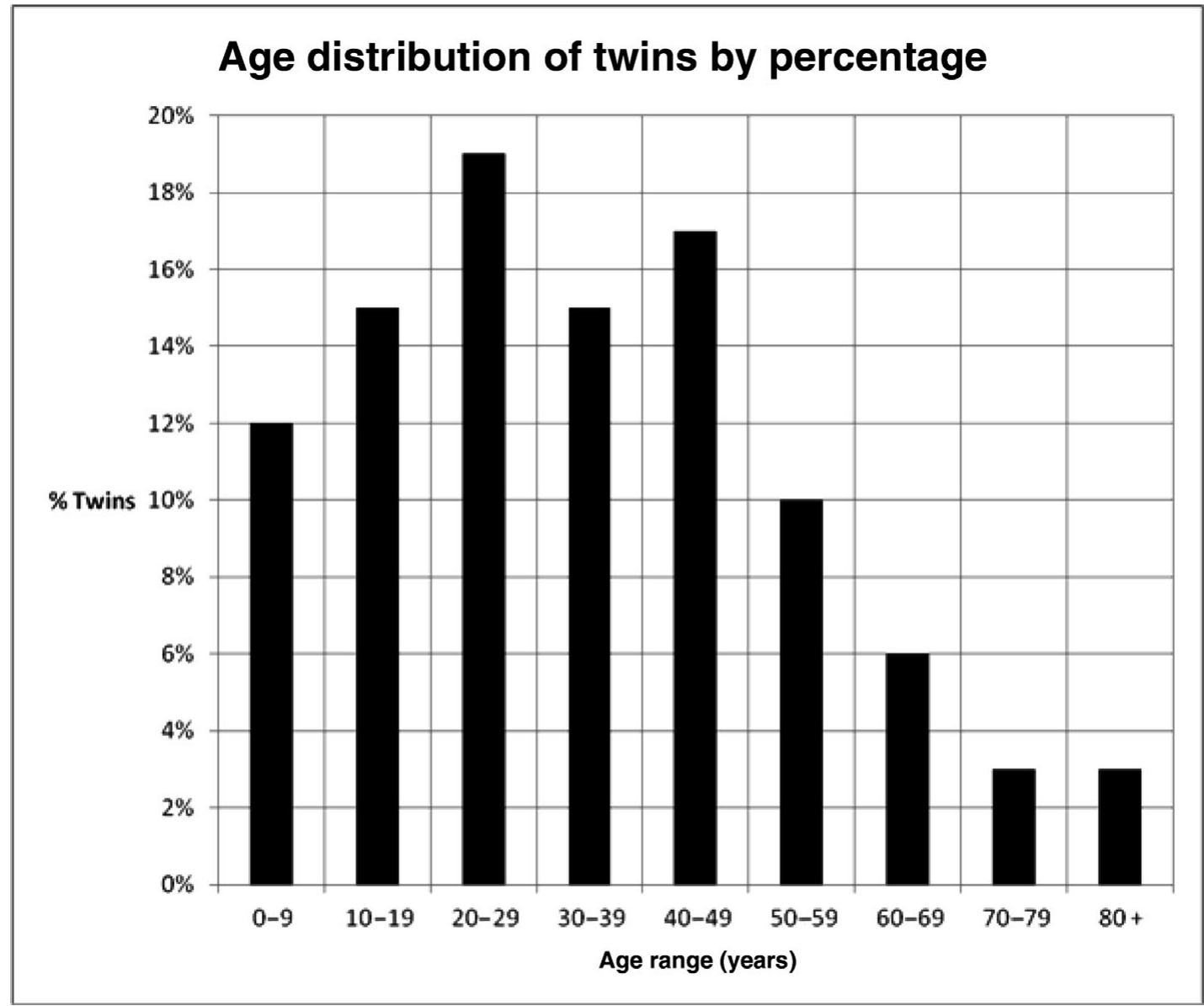

FIGURE 1

Age distribution of the ATR members.

A key avenue for the ATR's twin recruitment is through AMBA. There is a strong and long history of the two organizations working to support each other's needs. Other avenues of recruitment are the offer of a free Twin Booklet to women who are pregnant with twins, which provides the ATR with an opportunity to follow-up with recruitment once the twins are born; Twins Plus Festivals (read further under Promoting the ATR and Research Involving Twins); and general media exposure on twin research findings.

The integration of the Western ATR (WATR), a population-based sample of twin pairs from 1974 onwards, has provided sustainability, prevented duplication of recruitment, and combines expertise. WATR identifies twins via state birth records, making this cohort an important sample epidemiologically (Hopper et al., 2006; Lee \& Palmer, 2006). The peak in recruitment, starting in 1990, was the result of a media campaign launched by the incoming Director that year. The increase in twin recruitment in 2011 and 2012 reflects integration with the WATR and the ATR's raised profile in the media (See Figure 3).

\section{Participation in Research}

Once twins join the ATR they are invited to participate in appropriate and approved studies. Invitations are extended to twins depending on the requirements of the study, and the profile and the interest areas of the twin members.

The experience with the ATR and associated studies is critical to maximizing participation in studies. To this end, the ATR maintains a quality assurance program that incorporates surveys of random samples of participants in all studies to ascertain the participant's perspectives. The collected information is analyzed and used to inform continual improvements and modifications to ensure expectations are being satisfied.

The ATR provides a suite of services to twins in general. For example, it plays a key role in the funding, organization, hosting, and promotion of the Australian Twin Plus Festival.

The ATR endeavors to proactively maintain its relationship with twin members through regular communication. It updates members on studies and twin-related 


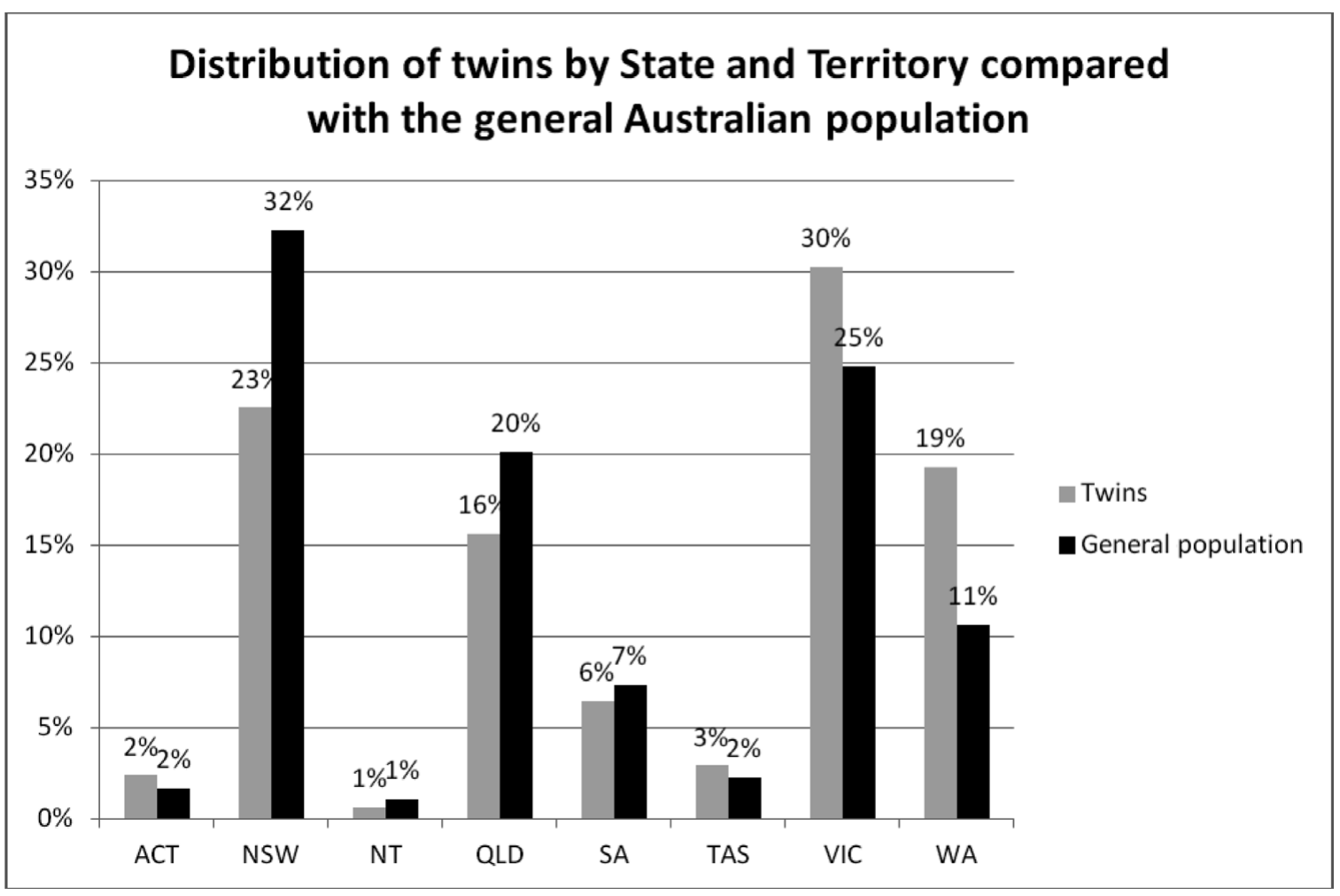

\section{FIGURE 2}

Geographic distribution of ATR members against the Australian general population.

news and events via its Web site (www.twins.org.au), quarterly e-News (www.twins.org.au/communicationsmedia/e-news), and social media channels (including Facebook and Twitter). Social media has provided a forum for twins to not only communicate with the ATR, but with the twin membership, providing opportunities to exchange experiences and ideas.

\section{Research Services}

Maintaining a high level of recruitment and engagement of twins provides researchers with a larger sample of willing participants across Australia. The ATR welcomes approaches from researchers across all disciplines on condition that there is an Australian-led investigator responsible for obtaining ethics approval.

The ATR promotes the value of twins to researchers by informing them of the ways studies involving twins can help understand epidemiological and clinical problems with a genetic and environmental perspective.

The ATR has developed a set of Guidelines, 'Working with the ATR', and an accompanying Data Transfer Agreement (DTA; http://www.twins.org.au/researchers/registryinformation). These documents facilitate clear and transparent discussions between the ATR and researchers by outlining the steps involved in interacting with the ATR, from the application through to rolling out studies and the returning of cleaned study data to the ATR for archiving. The Guidelines clearly outline the responsibilities of both parties throughout the collaborative relationship.

Researchers are required to submit an Expression of Interest. This allows initial timetabling and discussion around feasibility. The ATR can provide In Principle approval, which can be referred to in funding applications (see application process www.twins.org.au/application-process). The ATR can provide cost estimates of twin recruitment for inclusion in grant applications and assist with study approach materials sent to the twins.

Recruitment of study participants can commence once ethics approval is obtained. The initial approach to twins is handled by the ATR. Experienced ATR staff work closely with researchers to ensure the best possible response by providing clear and consistent information about the study's aims and requirements. Researchers are required to reimburse ATR for direct costs (i.e., material and labor expenses) associated with recruitment for their projects.

When a study is completed and the data is checked and cleaned, the ATR requests a copy of the data for its archives and possible future re-use for ethically approved studies. All publications are sent to the ATR for open access and can be viewed on the ATR Web site. This is in keeping with NHMRC recommendations (Australian Government 


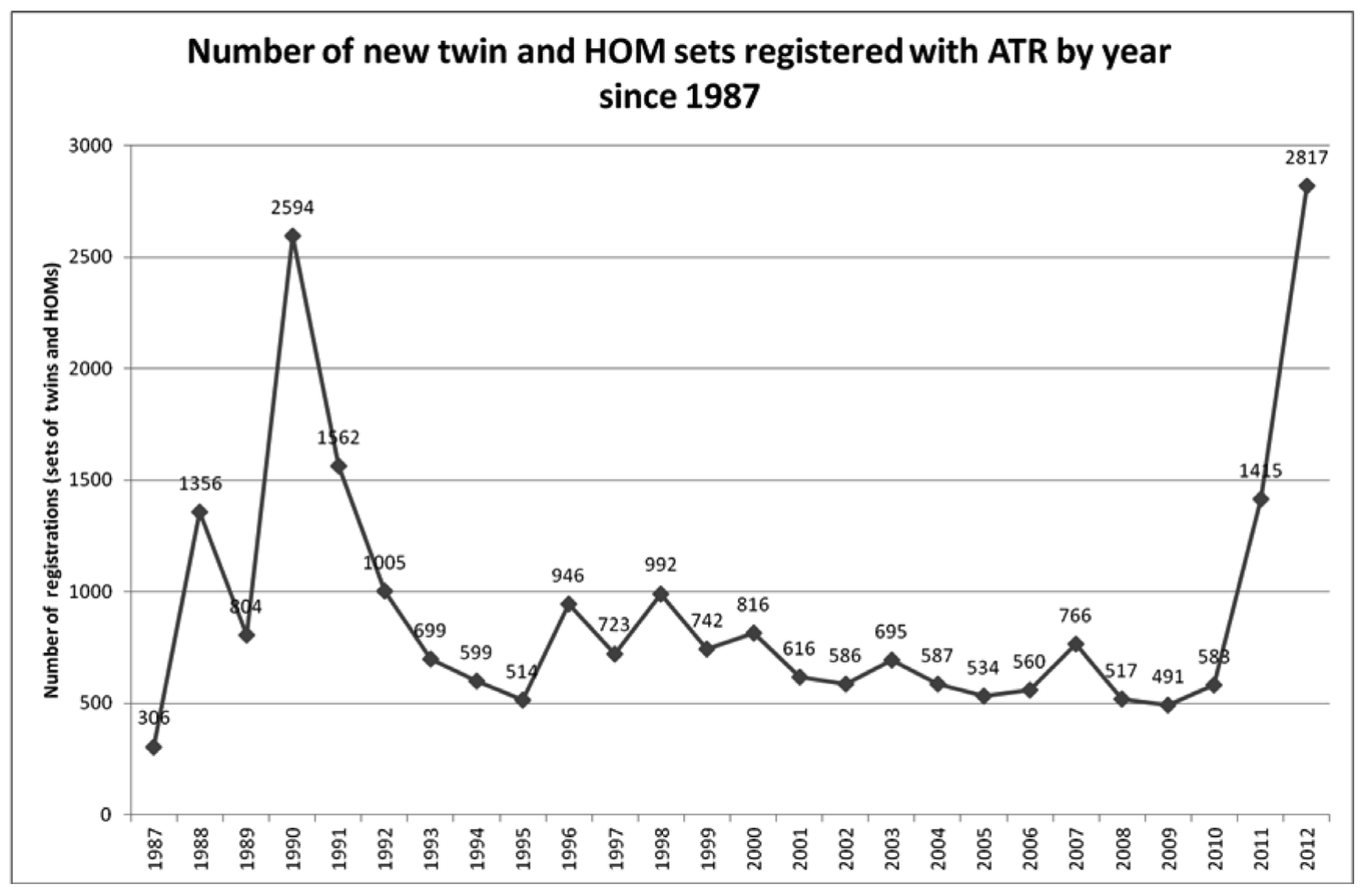

FIGURE 3

Annual twin recruitment over the last 25 years.

National Health and Medical Research Council, 2012). The ATR is also working to offer the capacity to back up biospecimen samples collected by projects in a biobank.

Researchers have used various different twin designs to help answer their research questions (see Table 2).

\section{Promoting the ATR and Research Involving Twins}

The ATR has run workshops almost annually for 30 years to encourage the exchange of ideas, offer training in twin research methodologies, and provide networking opportunities for researchers. The ATR exhibits at relevant research conferences to promote its service to a wider audience. It also provides travel grants to researchers presenting results from twin studies at such conferences. These initiatives highlight the power of twin studies under the theme 'Making studies involving twins an integral part of a researcher's repertoire'.

Community updates are sent out quarterly to past and current researchers. The ATR continues professional networking in the research community to assist with collaborations.

The ATR helped instigate the International Network of Twin Registries (INTR) by hosting a meeting in March 2011, and is playing a critical leadership role in enabling global twin studies to be conducted utilizing the more than 26 twin registries across the world involved with INTR (Buchwald \& Sung, 2012).

\section{Twins Plus Festival}

In March 2011, the ATR hosted a national Twins Plus Festival in Melbourne (see Figure 4). This was an opportunity for twins and HOM of all ages to get together and celebrate with friends and families. The festival was also an opportunity for the ATR and several research groups to hold exhibitions and engage with the twins, highlighting areas of their research, and showing their appreciation for the massive contribution Australian twins have made to research. The 3,000 plus attendees were entertained by a variety of performers and participated in a range of activities. Media coverage was extensive and international (www.twinsfestival.com.au).

\section{ATR Branding and Web Site}

In 2011 the ATR re-branded its 'look and feel'. The updated stationery and website reflect these changes. Through the website, researchers can access the Research Application Kit and information on ATR workshops, travel grants, and past and current studies and publications. Twins can access information about studies, twin resources and events, and register or update contact details. The ATR has an active 
TABLE 2

Some Examples of Australian Twin Studies

\begin{tabular}{|c|c|c|}
\hline Study design & Trait & Findings \\
\hline \multirow[t]{3}{*}{ Classic twin model } & Epilepsy and syncope & $\begin{array}{l}\text { Genetic factors play a role in epilepsy and syncope (fainting (Berkovic et al., 1996, 1998; } \\
\text { Klein et al., 2012; Vadlamudi et al., 2010). }\end{array}$ \\
\hline & Cervical cancer & $\begin{array}{l}\text { Possible to measure human papilloma virus genotype from archival pap smears (Moore } \\
\text { et al., 2012; Tabrizi et al., 2010). }\end{array}$ \\
\hline & Melanoma & $\begin{array}{l}\text { Difference in mole colour and size are largely genetic in origin but environment does play a } \\
\text { significant contribution to the color of moles (McGregor et al., 1999). }\end{array}$ \\
\hline $\begin{array}{l}\text { Co-Twin control study - } \\
\text { Disease discordant }\end{array}$ & Epilepsy & Obstetric events are not associated with the risk of febrile seizures (Helbig et al., 2008). \\
\hline $\begin{array}{l}\text { Co-Twin Control Study - } \\
\text { Exposure discordant }\end{array}$ & $\begin{array}{l}\text { Smoking and bone } \\
\text { density }\end{array}$ & $\begin{array}{l}\text { Women who smoke as adults have reduced bone density at menopause sufficient to double } \\
\text { their risk of bone fractures (Hopper \& Seeman, 1994). }\end{array}$ \\
\hline \multirow[t]{2}{*}{ Longitudinal study } & Eating disorders & $\begin{array}{l}\text { The most significant time of risk for the development of high levels of weight and shape } \\
\text { concern was 13-15 years of age (Wade et al., 2008; Wilksch \& Wade, 2009, 2010). }\end{array}$ \\
\hline & Oral health/dentistry & $\begin{array}{l}\text { Environmental and epigenetics factors likely play a role in the timing of tooth emergence } \\
\text { and bacterial colonization (Bockmann et al., 2011). }\end{array}$ \\
\hline \multirow[t]{2}{*}{$\begin{array}{l}\text { Randomized controlled } \\
\text { trial }\end{array}$} & Emotional health & $\begin{array}{l}\text { Different parts of the brain are more or less heritable than others; for example, frontal cortex } \\
\text { versus sub-cortical. White-matter of the brain has higher heritability than gray-matter. This } \\
\text { has led to a randomized controlled trial to study the effect of targeted brain training to } \\
\text { boost resilience (Gatt et al., 2012). }\end{array}$ \\
\hline & Bone density & $\begin{array}{l}\text { Calcium supplementation increases bone density over } 12-18 \text { months but these gains were } \\
\text { not maintained to } 2 \text { years (Cameron et al., 2004). }\end{array}$ \\
\hline Issues specific to twins & $\begin{array}{l}\text { Twin children social } \\
\text { development }\end{array}$ & $\begin{array}{l}\text { For most twin pairs, staying together in the first year of school is a social support (Bekkhus et } \\
\text { al., 2011; Staton et al., 2012). }\end{array}$ \\
\hline Epigenetics & Birth weight & $\begin{array}{l}\text { Birth weight is associated with epigenetic differences in genes associated with growth, } \\
\text { metabolism, and cardiovascular function (Gordon et al., 2011; Saffery et al., 2012). }\end{array}$ \\
\hline
\end{tabular}

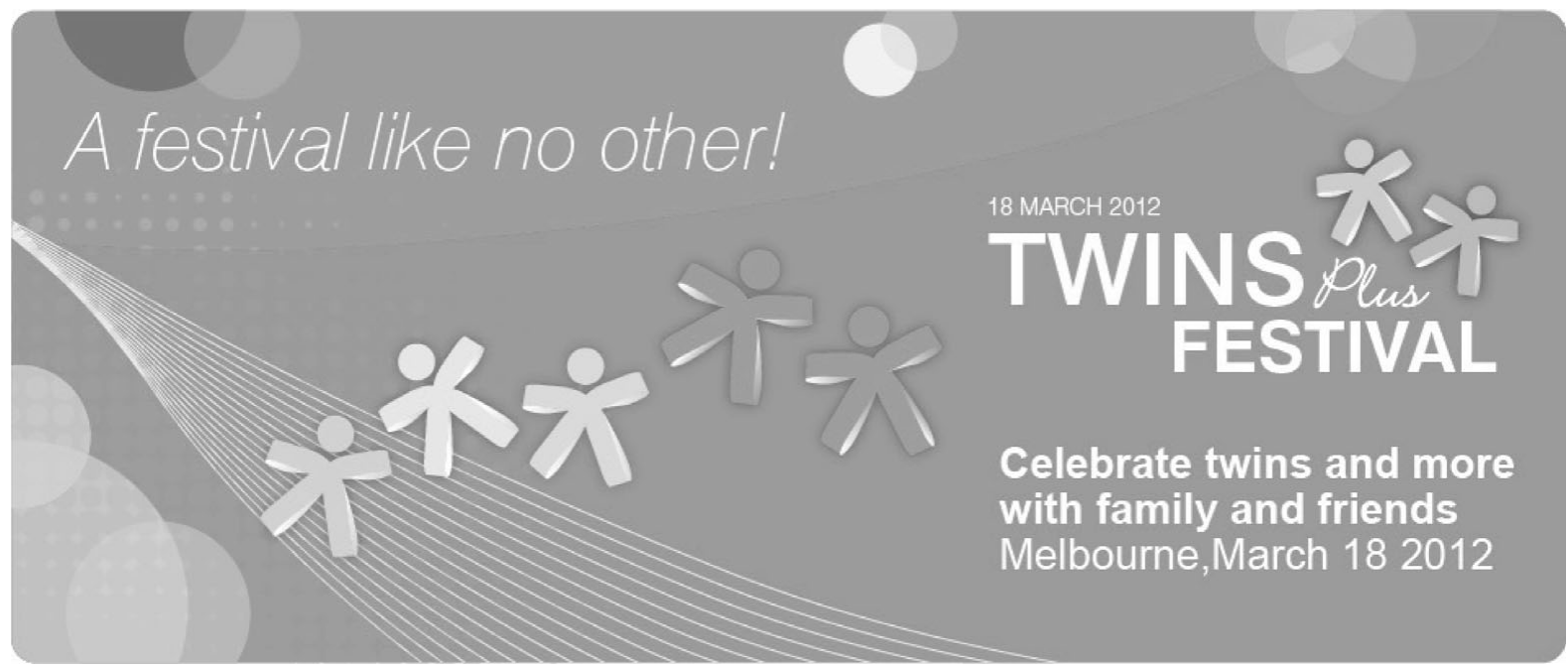

\section{FIGURE 4}

Flyer for the Twins Plus Festival in 2012.

following on both Facebook and Twitter, servicing the needs of the twins. The ATR's photo gallery is one of the most popular sites, illustrating the diversity of our membership (www.twins.org.au; see Figure 5).

\section{Media Releases}

Regular media releases effectively raise the profile of twin research benefits and outcomes to the wider community. (See http://www.twins.org.au/communicationsmedia/media-releases.)

\section{Current and Future Initiatives}

In addition to the ongoing twin and research service delivery, the strategic direction and focus of the ATR currently revolves around five key priorities and initiatives:

1. Continue the implementation of the DTA for all new studies run through the ATR. This will allow the possible re-use of data for future approved studies.

2. Continue to collect contact details of mothers pregnant with twins and provide a free Twin Pregnancy Booklet. 


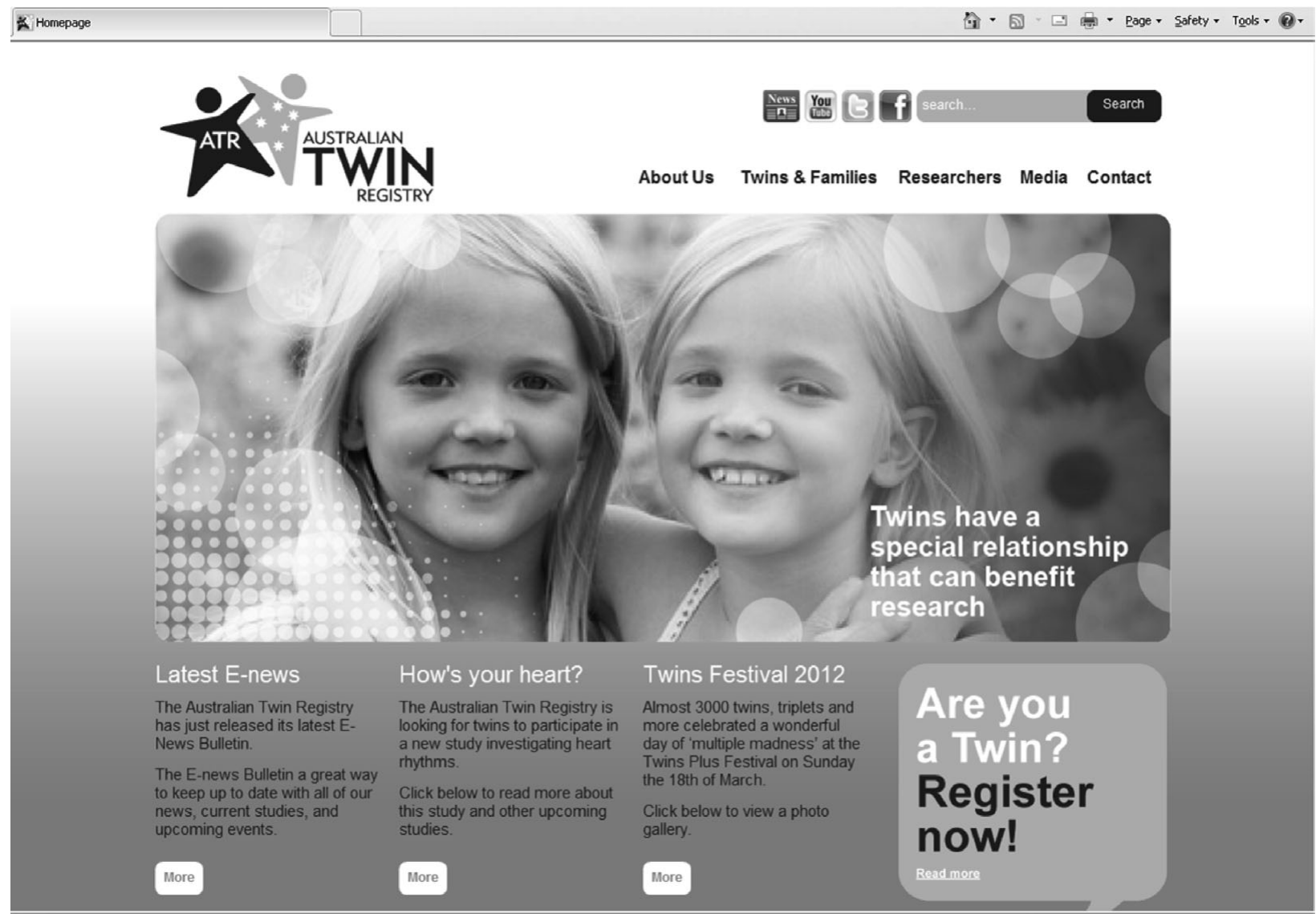

\section{FIGURE 5}

ATR website.

This cohort could readily be approached for twin pregnancy projects.

3. Increase our service offering to researchers by providing a web-based study management system, The Ark. This will allow researchers to conduct data management, study management, laboratory information management, and enable statistical analyses for all researchers in a secure and cost-effective way. This resource can be accessed from anywhere in the world through the Internet.

4. Implement a Health and Life Style Questionnaire to be sent to all ATR twins to form the basis of new research studies. Information gathered from the questionnaire will enable more information to be available to researchers and assist with specific targeting for selective eligibility criteria. This will be ongoing and sent to all new members.

5. Continue to support the development of the INTR that comprises more than 26 twin registries over 17 countries, which was showcased at the 2012 meeting of the International Society of Twin Studies in
Florence (Buchwald \& Sung, 2012). This global collaborative approach will leverage the benefits, resources, and experiences of registries from around the world.

These initiatives will improve the level of service and support the ATR can offer researchers and enhance medical and scientific research involving twins.

\section{Conclusion}

The ATR has benefited from the support and funding from the NHMRC. This has allowed it to develop, modernize, and improve its procedures and infrastructure so that it can continue to play a major role as a prominent national research resource. Interest in epigenetics, advances in the field of biotechnology, and accelerated interest in the human genome highlight the potential twin studies have to play.

The ATR will continue to expand its service to research so as to fulfill its vision: 'To realize the full potential of research involving twins to improve the health and well-being of all Australians'. 


\section{Acknowledgments}

We acknowledge all the twins and HOMs who have voluntarily enrolled with the ATR and contributed so much to the research it has supported. We also acknowledge the help of Kate Murphy (Manager), Jennifer Boadle (Studies Coordinator), Kelly Aujard (Informatics Manager), and Nilmini Jayasuriya (Assistant Manager) in preparing the information and material for this article. Financial support for the ATR comes from the National Health and Medical Research Council (NHMRC) Enabling Grant \#628911. JLH is an Australia Fellow of the NHMRC.

\section{References}

Australian Bureau of Statistics. (2011). Australian Demographic Statistics. Retrieved from http://www.abs.gov.au/ ausstats/abs@.nsf/mf/3101.0/

Australian Government National Health and Medical Research Council. (2012). Dissemination of Research Findings, National Health and Research Council revised policy on dissemination of research findings. Retrieved 2 August 2012, from www.nhmrc.gov.au/grants/policy/disseminationresearch-findings

Bekkhus, M., Staton, S., Borge, A. I. H., \& Thorpe, K. (2011). Conflict, closeness and comfort: The inter-twin relationship as a risk factor for behavioral difficulties. Twin Research and Human Genetics, 14, 444-451.

Berkovic, S. F., Howell, R. A., Hay, D. A., \& Hopper, J. L. (1998). Epilepsies in twins: Genetics of the major epilepsy syndromes. Annals of Neurology, 43, 435445.

Berkovic, S. F., McIntosh, A., Howell, R. A., Mitchell, A., Sheffield, L. J., \& Hopper, J. L. (1996). Familial temporal lobe epilepsy: A common disorder identified in twins. Annals of Neurology, 40, 227-235.

Bockmann, M. R., Harris, A. V., Bennett, C. N., Odeh, R., Hughes, T. E., \& Townsend, G. C. (2011). Timing of colonization of caries-producing bacteria: An approach based on studying monozygotic twin pairs. International Journal of Dentistry, 2011, 571-573.

Buchwald, D., \& Sung, J. (2012). Intrepid: An international network of twin registries. Twin Research and Human Genetics [abstract], 15, 179-180.

Cameron, M. A., Paton, L. M., Nowson, C. A., Margerison, C., Frame, M., \& Wark, J. D. (2004). The effect of calcium supplementation on bone density in premenarcheal females: A co-twin approach. Journal of Clinical Endocrinology \& Metabolism, 10, 4916-4922.

Gatt, J. M., Korgaonkar, M., Schofield, P. R., Harris, A., Clark, C. R., Oakley, K., ... Williams, L. M. (2012). The TWIN-E project in emotional wellbeing: Study protocol and preliminary heritability results across four MRI and DTI measures. Twin Research and Human Genetics, 15, 419441.

Gordon, L., Joo, J. H., Andronikos, R., Ollikainen, O., Wallace, E. M., Umstad, M. P., .. Craig, J. M. (2011). Expression discordance of monozygotic twins at birth: Effect of intrauterine environment and a possible mechanism for fetal programming. Epigenetics, 6, 579-592.

Helbig, I., Lawrence, K. M., Connellan, M. M., Torn-Broers, Y., Vadlamudi, L., Eckhaus, J., ... Berkovic, S. F. (2008). Obstetric events as a risk factor for febrile seizures: A community-based twin study. Twin Research and Human Genetics, 11, 634-640.

Hopper, J. L., \& Seeman, E. (1994). The bone density of female twins discordant for tobacco use. New England Journal of Medicine, 330, 387-392.

Hopper, J. L., Trelor, S. A., de Klerk, N., \& Morley, R. (2006). Australian Twin Registry: A nationally funded resource for medical and scientific research, incorporating match and WATCH. Twin Research and Human Genetics, 9, 707711.

Klein, K. M., Xu, S. S., Lawrence, K., Fischer, A., \& Berkovic, S. F. (2012). Evidence for genetic factors in vasovagal syncope: A twin-family study. Neurology, 79, 561-565.

Lee, J. D., \& Palmer, L. J. (2006). The Western Australian Twin Registry: A population-based register of adult and child multiples. Twin Research and Human Genetics, 9, 712717.

McGregor, B., Pfitzner, J., Zhu, G., Grace, M., Eldridge, A., Pearson, J., ... Martin, N. G. (1999). Genetic and environmental contributions to size, color, shape, and other characteristics of melanocytic naevi in a sample of adolescent twins. Genetic Epidemiology, 16, 4053.

Moore, E. E., Wark, J. D., Hopper, J. L., Garland, S. M., \& CeCaGeEn Study Group. (2012). The roles of genetic and environmental factors on risk of cervical cancer: A review of classical twin studies. Twin Research and Human Genetics, 15, 79-86.

Saffery, R., Morley, R., Carlin, J. B., Joo, J. H., Ollikainen, M., Novakovic, B., ... Craig, J. M. (2012). Cohort profile: The Peri/postnatal Epigenetic Twins Study (PETS). International Journal of Epidemiology, 41, 5556.

Staton, S., Thorpe, K., Thompson, C., \& Danby, S. (2012). To separate or not to separate?: Parental decision making regarding the separation of twins in the early years of schooling. Journal of Early Childhood Research, 10, 196208.

Tabrizi, S. N., Taylor, N., McCullough, M. J., Phillips, G., Wark, J., ... CeCaGeEnStudy Group. (2010). Human papillomavirus genotype detection from archival Papanicolaoustained cervical smears. Cancer Cytopathology, 118, 482489.

Torgersen, S. (1979). The determination of twin zygosity by means of a mailed questionnaire. Acta Geneticae Medicae et Gemellogiae, 28, 225-236.

Vadlamudi, L., Dibbens, L. M., Lawrence, K. M., Iona, X., McMahon, J. M., Murrell, W, Mackay-Sim, A., Scheffer, I. E., \& Berkovic, S. F. (2010). Timing of de novo mutagenesis: A twin study of sodium channel mutations. New England Journal of Medicine, 363, 13351340 . 
Wade, T. D., Byrne, S., \& Bryant-Waugh, R. (2008). The Eating Disorder Examination: Norms and construct validity with young and middle adolescent girls. International Journal of Eating Disorders, 41, 551-558.

Wilksch, S. M., \& Wade, T. D. (2009). An investigation of temperament endophenotype candidates for early emergence of the core cognitive component of eating disorders. Psychological Medicine, 39, 811-822.

Wilksch, S. M., \& Wade, T. D. (2010). Risk factors for clinically significant importance of shape and weight in adolescent females. Journal of Abnormal Psychology, 119, 206215. 


\section{University Library}

\section{- M M I N E R VA A gateway to Melbourne's research publications}

Minerva Access is the Institutional Repository of The University of Melbourne

Author/s:

Hopper, JL;Foley, DL;White, PA;Pollaers, V

Title:

Australian Twin Registry: 30 Years of Progress

Date:

2013-02-01

Citation:

Hopper, J. L., Foley, D. L., White, P. A. \& Pollaers, V. (2013). Australian Twin Registry: 30 Years of Progress. TWIN RESEARCH AND HUMAN GENETICS, 16 (1), pp.34-42. https:// doi.org/10.1017/thg.2012.121.

Publication Status:

Accepted manuscript

Persistent Link:

http://hdl.handle.net/11343/41877 